\title{
Identification of Proteins from Two-dimensional Gel Electrophoresis of Human Erythroleukemia Cells Using Capillary High Performance Liquid Chromatography/Electrospray-Ion Trap- Reflectron Time-of-flight Mass Spectrometry with Two-dimensional Topographic Map Analysis of In-gel Tryptic Digest Products
}

\author{
Yajuan Chen ${ }^{1}$, Xiaoying Jin ${ }^{1}$, David Misek ${ }^{2}$, Robert Hinderer ${ }^{2}$, Sam M. Hanash ${ }^{2}$ and \\ David M. Lubman ${ }^{1 *}$ \\ ${ }^{1}$ Department of Chemistry, School of Medicine, The University of Michigan, Ann Arbor, MI 48109-1055, USA \\ ${ }^{2}$ Department of Pediatrics, School of Medicine, The University of Michigan, Ann Arbor, MI 48109-1055, USA
}

SPONSOR REFEREE: Prof. Mehdi Moini, Department of Chemistry and Biochemistry, The University of Texas at Austin, Austin, TX 78712-1167, USA

\begin{abstract}
Protein spots from two-dimensional (2-D) gel electrophoresis of a human erythroleukemia cell line have been identified by analysis of the in-gel tryptic digests using capillary high performance liquid chromatography (HPLC) separation with on-line detection using electrospray ionization mass spectrometry (ESI-MS). This is performed using an electrospray/ion trap storage/reflectron time-of-flight mass spectrometer system (ESI-IT-reTOFMS). A 2-D topographic mapping display developed to process the on-line data acquired with this TOF system has been used to obtain mass identification of each peptide, even though the capillary HPLC only provides limited separation capability of the tryptic peptide mixtures studied herein. Using this method, a substantial fraction of the protein sequence can be covered and identified using the tryptic map. It is demonstrated that by entering the cell species, the approximate MW and $\mathrm{pI}$ range as determined by 2-D gel electrophoresis, and the tryptic peptide map into the database a unique match for identification of the protein generally results. It is also demonstrated that a much improved coverage of the protein sequence is obtained by this method relative to matrix-assisted laser desorption/ionization mass spectrometry (MALDI-MS). Copyright $($ C 1999 John Wiley \& Sons, Ltd.
\end{abstract}

Received 30 July 1999; Accepted 30 July 1999

The use of 2-D gel electrophoresis has become an important method in monitoring changes in the protein expression of cells. This method can separate out thousands of proteins in a cell which can then be visualized as protein spots using a variety of staining methods. The 2-D gel method has become a key tool in cancer research where changes in protein expression as a function of tumor progression can be followed. The 2-D gel method though only provides separation of proteins, and does not in itself provide a means of identification or of detailed sequence information. A method for unique identification of the gel-separated proteins is required to understand the changes occurring in the cancer process.

In recent work, mass spectrometry has become a powerful method for analysis of proteins from 2-D gel separations. There are several strategies that have been used to identify

\footnotetext{
*Correspondence to: D. M. Lubman, Department of Chemistry, The University of Michigan, Ann Arbor, MI 48109-1055, USA.

Contract/grant sponsor: National Institutes of Health; Contract/grant number: 2-R01GM49500-5.

Contract/grant sponsor: National Science Foundation; Contract/grant
} number: BIR-9513878. or sequence protein spots via mass spectrometry. One method, which uses peptide mass fingerprinting, ${ }^{1-24}$ involves the measurement of the peptide map generated by enzymatic or chemical sequence-specific cleavage of a protein. This method has been used with MALDI-MS and LC/ESI-MS for database searching and identification of proteins isolated by 2-D gel electrophoresis. This method is particularly effective for identifying proteins if accompanying information such as the molecular weight, $\mathrm{pI}$ and species is available. It has been shown that as few as three or four peptides from the protein digestion can provide sufficient selectivity based upon their unique sequences to identify the protein from the database. ${ }^{16,21}$ In addition, the technique is sufficiently selective so that even if more than one protein digest is present, the unique peptide fingerprints can be used to distinguish the proteins. In addition, the technique inherently becomes more specific in its identification as the peptide coverage of the protein increases. Moreover, if sufficient protein coverage is achieved then the presence of modifications can be identified. These modifications can be pinpointed by MS/MS using ion trap or triple quadrupole mass spectrometers. ${ }^{9,17}$ 
In the present work, capillary HPLC (cHPLC) separation and identification of peptides from protein digests obtained from a 2-D gel electrophoresis separation of proteins from a human erythroleukemia (HEL) cell line are used for on-line analysis of these protein digests with ESI-MS. The on-line cHPLC separation has been coupled to electrospray ionization for analysis using an ion trap storage/reflectron time-of-flight mass spectrometer. The capillary separation is then plotted versus the mass spectrum in a 2-D topographic map where each peptide can be uniquely displayed for accurate analysis of the peptide digest products despite the limited resolution of the HPLC separation. It is shown by using this method to obtain digest results, along with the species, molecular weight and $\mathrm{pI}$ of the protein from the gel, that unique identification of the protein is obtained. This unique identification is based on the relatively extensive coverage of the protein obtained by LC/ESI-MS relative to MALDI-MS where more than one possible match may be obtained.

\section{EXPERIMENTAL}

\section{Materials}

Chemicals including 1, 4-dithiothreitol (DTT), iodoacetamide and ammonium, bicarbonate were purchased from ICN Biomedicals Inc. (Costa Mesa, CA, USA). Organic solvents including HPLC grade acetonitrile, acetone and methanol were obtained from Sigma-Aldrich (St. Louis, MO, USA). $\alpha$-Cyano-4-hydroxycinnamic acid ( $\alpha \mathrm{CHCA})$ and trifluoroacetic acid (TFA) were also obtained from Sigma-Aldrich. Coomassie Brilliant Blue R-250 was supplied by Bio-Rad (Hercules, CA, USA). Trypsin was purchased from Promega (Madison, WI, USA). All chemicals were used without further purification.

The fittings, ferrules and frits used for capillary HPLC column packing were purchased from Valco Instruments Co. Inc. (Houston, TX, USA).

\section{In-gel digestion of proteins from 2-D gels}

Proteins from human erythroleukemia (HEL) cell extracts were separated by 2-D gel electrophoresis, with $\mathrm{pH}$ 4-8 carrier ampholytes isoelectric focusing (IEF) as the first dimension and sodium dodecyl sulfate (SDS) polyacrylamide as the second dimension. The 2-D gels used in this study were run at the Department of Pediatrics, the University of Michigan, according to the procedure previously described. ${ }^{25}$ Proteins were visualized by staining the gels with $1 \mathrm{~L}$ of $0.1 \%$ Coomassie Brilliant Blue R-250 in $50 \% \mathrm{v} / \mathrm{v}$ methanol and $10 \% \mathrm{v} / \mathrm{v}$ acetic acid solution for about $1.5 \mathrm{~h}$, followed by destaining the gels with $50 \%$ $\mathrm{v} / \mathrm{v}$ methanol and $10 \% \mathrm{v} / \mathrm{v}$ acetic acid solution several times until the protein spots were clearly observed on the gels.

Protein spots were cut from the 2-D gels, followed by ingel tryptic digestion. The in-gel digestion procedure was modified from a previously reported protocol ${ }^{14}$ : (1) gel spots were cut into smaller pieces and placed into $0.5 \mathrm{~mL}$ Eppendorf tubes and washed with washing buffer $(50 \%$ acetonitrile and $50 \% 200 \mathrm{mM} \mathrm{NH} \mathrm{NCO}_{3}, \mathrm{pH}=8$ ) twice, each for $30 \mathrm{~min}$. (2) After removing the wash, $100 \mu \mathrm{L}$ of washing buffer and $3 \mu \mathrm{L}$ of $45 \mathrm{mM}$ DTT were added and the samples were incubated at $37^{\circ} \mathrm{C}$ for $20 \mathrm{~min}$. (3) $6 \mu \mathrm{L}$ of $100 \mathrm{mM}$ iodoacetamide were added to the samples above, followed by $40 \mathrm{~min}$ incubation at $37^{\circ} \mathrm{C}$. (4) The supernatant was removed, and the gel pieces were washed with the washing buffer for $30 \mathrm{~min}$ once, and $15 \mathrm{~min}$ twice. (5) The gel pieces were then brought to complete dryness in a SpeedVac (Labconco) and about $1-2 \mu \mathrm{g}$ of trypsin in $50 \mathrm{mM} \mathrm{NH}_{4} \mathrm{HCO}_{3}(\mathrm{pH}=7.8)$ were used to rehydrate the gel pieces (the amount of $50 \mathrm{mM} \mathrm{NH} \mathrm{NHCO}_{3}$ was sufficient to cover the gel pieces), and the samples were incubated at $37^{\circ} \mathrm{C}$ for about $20 \mathrm{~h}$. (6) The protein digest was extracted from the gel pieces by the extraction buffer (1\% TFA, 60\% acetonitrile) three times for $30 \mathrm{~min}$ at room temperature. The extracts were combined and dried in a SpeedVac. Usually 12 pieces of gels were available for each protein spot analyzed. Part of the in-gel protein tryptic digest was used for MALDI analysis, while the remainder could be analyzed by capillary HPLC/ESI-ion trap-reflectron TOFMS. Usually the equivalent of 3-5 gel pieces were used for HPLC/ESI-IT-reTOF mass spectrometric analysis depending on the intensity of the spot.

\section{Capillary HPLC/ion trap-reflectron TOF analysis of in- gel protein tryptic digests}

The HPLC column used in this study was a C18 reversedphase capillary column which was packed in our laboratory using a high-pressure syringe pump (ISCO, $\mu$ LC-500 micropump, Lincoln, NE, USA). The solvent used in this packing procedure was HPLC grade methanol. The column is a $149 \mu \mathrm{m}$ i.d./368 $\mu \mathrm{m}$ o.d. fused silica capillary (Polymicro Technologies Inc., Phoenix, AZ, USA) about 8$10 \mathrm{~cm}$ in length, packed with $5 \mu \mathrm{m}$ particle size, $300 \AA$ pore size C18 packing material (Vydac, Hesperia, CA, USA). The HPLC pump used for this analysis by on-line capillary HPLC/MS was a Star 9012 solvent delivery system (Varian Associates, Inc., Houston, TX, USA). A pre-column split of solvent was used to reduce the flow rate from 200 to $3-5 \mu \mathrm{L} /$ min, which was suitable for capillary HPLC separation. The running buffers used were buffer A: $0.1 \%$ TFA, $\mathrm{H}_{2} \mathrm{O}$ (MQ), and buffer B: $0.08 \%$ TFA, acetonitrile with a gradient of 0 to $80 \%$ for buffer B in 40 min during the separation.

An ion trap storage-reflectron time-of-flight mass spectrometer which consists of a differentially pumped reflection time-of-flight mass spectrometer (Model D850) interfaced to a quadrupole ion trap storage device (Model C1251, R. M. Jordan Co., Grass Valley, CA, USA) was used for mass detection. The details of this instrument have been described in a previous publication. ${ }^{26,27}$ The HPLC column effluents were delivered through a $40 \mu \mathrm{m}$ i.d. fused silica capillary directly to the electrospray assembly. The stainless steel electrospray needle was maintained at $\sim+4 \mathrm{kV}$ relative to a heated stainless steel inlet capillary tube $\left(0.5 \mathrm{~mm}\right.$ i.d., $\left.120^{\circ} \mathrm{C}\right)$ which was held at ground. A nitrogen gas stream was used as the carrier gas to stabilize and optimize the electrospray. The heated capillary tube transported ions to the interface region which was pumped to a pressure of less than 1 Torr, where a cylindrical lens $(+100 \mathrm{~V})$ and a $325 \mu \mathrm{m}$ orifice skimmer (grounded) were aligned co-axially to focus the ions into the high-vacuum chamber. The ions traversing through the skimmer were then focused by an Einzel lens into the ion trap. The ions were stored in the ion trap under a preset radio frequency (RF) of $1.1 \mathrm{MHz}$ and voltage of $1400 \mathrm{~V}(\mathrm{Vpp})$ for $250 \mathrm{~ms}$, corresponding to a sampling rate of $4 \mathrm{~Hz}$. A dc pulse was subsequently applied to the exit endcap of the ion trap to eject the stored ions into the reflectron time-of-flight for 
mass analysis. The ions were detected by a $40 \mathrm{~mm}$ triplemicrochannel plate detector (Model C2501, R. M. Jordan Co., Grass Valley, CA, USA). The mass signals were collected using a $250 \mathrm{MHz}$ transient digitizer (model 9846, Precision Instruments Inc., Knoxville, TN, USA) embedded in a Pentium II 400-MHz PC-compatible computer (Dell, Round Rock, TX, USA). A user-developed 2-D false-color image data acquisition and processing software was used to display the on-line separation and mass detection result on the computer screen. A TOF sampling time window width of $150 \mu \mathrm{s}$, which corresponds to a $\mathrm{m} / \mathrm{z}$ range of 200 to $\sim 1500 \mathrm{Da}$, was generally used in our study.

\section{MALDI analysis of in-gel protein tryptic digests}

The TOF mass spectrometer used in these studies was a modified Wiley-McLaren design (manufactured by R. M. Jordan Co., Grass Valley, CA, USA) with a field-free drift length of $1 \mathrm{~m}$. The laser source used was a DCR-11 Nd:YAG laser system (Spectraphysics, San Jose, CA, USA) which produced $355 \mathrm{~nm}$ radiation with a pulse width of 5$6 \mathrm{~ns}$ and a power density of $\sim 5 \times 10^{6}$ to $1 \times 10^{7} \mathrm{~W} / \mathrm{cm}^{2}$ for MALDI-MS. The detector was an $18 \mathrm{~mm}$ triple-microchannel plate (MCP) detector (R. M. Jordan Co., Grass Valley, CA, USA). A simple high-voltage transistor switch, which was developed to provide a voltage drop of $3000 \mathrm{~V}$ with a $75 \mathrm{~ns}$ fall time, was used to perform pulsed delayed extraction (PDE) to improve the resolution. ${ }^{28,29}$ Data were recorded using a Lecroy $9350 \mathrm{M}$ digital oscilloscope (LeCroy Corp., Chestnut Ridge, NY, USA) and processed on a Gateway $586166 \mathrm{MHz}$ computer. All spectra were obtained from an average of 50 laser pulses.

The matrix used in these experiments was a saturated solution of $\alpha$-cyano-4-hydroxycinnamic acid ( $\alpha \mathrm{CHCA})$ in acetone containing 1\% TFA. The in-gel tryptic digests of the proteins from the 2-D gels were dissolved in about $7 \mu \mathrm{L}$ of MQ water and $2 \mu \mathrm{L}$ of the above sample solution were mixed with an equal volume of the matrix on the probe and allowed to dry at room temperature prior to MALDI analysis. The remainder of the sample $(\sim 5 \mu \mathrm{L})$ was used for the capillary HPLC/ESI-ion trap-reflectron TOF analysis.

\section{Database search for protein sequence identification}

The peptide maps generated from in-gel tryptic digestion of protein spots from 2-D gels as analyzed by on-line capillary HPLC/ESI-ion trap-reflectron TOFMS and MALDITOFMS can be used to search against a database for their identities. The database searching program used in our study was the MS-Fit sequence database search tool in the Protein Prospector program, which was designed at UCSF. The database used was SwissProt.r03.07.99. Specific information, such as protein species, molecular weight range, pI range, enzyme name, cysteine modifications, etc., required input into the database before the search in order to narrow the search range to find the correct match.

The database search program considers that the input peptides, which result from protein enzymatic digestion, are in the form of $\mathrm{MH}^{+}$, i.e. singly charged ions. Therefore, a different search algorithm must be applied to the peptide map generated by on-line capillary HPLC/ESI-ion trapreflectron TOFMS from the map generated by MALDITOFMS. The peptides detected by MALDI/TOFMS are usually singly charged, where the values obtained could be input directly into the search program to identify the protein.
The peptides detected by on-line capillary HPLC/ESI-MS could be in the form of singly, doubly or triply charged ions. These ions must be converted into the $\mathrm{MH}^{+}$form in order to search for their corresponding peptide fragments in the database. For an unknown protein, the charge state of its digest peptide peaks could be obtained by examining the isotope distribution of the peaks. Alternatively, most protein tryptic digest peptides detected are doubly charged, especially at the RF voltage applied to the ring electrode of the ion trap in this work. The optimal mass/charge storage range depends on the RF voltage ${ }^{30}$ and it was adjusted to optimally store the mass range for detection of doubly charged ions from tryptic digests. In order to search for the identity of a protein, we first assume that all the peptide ions detected are doubly charged, convert them into the form of $\mathrm{MH}^{+}$, and input them into the database to search. In most cases, this step alone can provide a single protein identity match. For the unmatched peptide values, we find their corresponding $\mathrm{m} / \mathrm{z}$ before the first step, consider them as singly charged, combine them with the matched peptides in the first step, and input them into the database to search. The same protein identity as the first step would show up with additional peaks matched. The third step was similar in that for the unmatched peptides in the second step, find their corresponding $\mathrm{m} / \mathrm{z}$ before the first step, consider them as triply charged, convert them into the $\mathrm{MH}^{+}$form, combine them with the matched peptides in the second step, and input them into the database to search. The same protein identity would still be found for the search with several additional peaks matched. In the end, there would usually be a couple of peaks that were not matched due to contamination. In order to reduce the complexity, for peptides analyzed by capillary HPLC/ESI-MS, the peaks with similar elution time on the total ion current (TIC) chromatogram and exact $\mathrm{m} / \mathrm{z}$ on the mass spectrum for all the protein spots analyzed were eliminated before the search was started. These were considered possible contaminants from the gels or from trypsin autolysis peptides.

\section{RESULTS AND DISCUSSION}

The image of the 2-D gel electrophoresis separation of a HEL cell extract is shown in Fig. 1. The protein spots marked with arrows on the 2-D gel image have been analyzed and identified by capillary HPLC/electrospray ionization-ion trap storage-reflectron TOFMS. Table 1 lists the database search result for the identities of each of these protein spots. In each case, the cell species, approximate MW and pI range obtained from the 2-D gel, and the tryptic peptide map obtained from digestion of the protein, are entered into the database. If sufficient coverage of the protein by the peptide map is obtained from the cHPLC/ ESI-IT-reTOFMS method, then a unique match is generally obtained from the database.

Figures. 2-5 show the 2-D false-color images of the online cHPLC/ESI-IT-reTOF mass spectrometric analysis of the tryptic digests of the spots labeled as \# 1,2, 3 and 8 on the 2-D gel. The 2-D plot consists of the elution time of the cHPLC separation plotted on the y-axis while the time-offlight or mass-to-charge ratio is plotted on the $\mathrm{x}$-axis. The plot results from monitoring the mass spectrum as a function of time and plotting the TIC chromatogram that results from the on-line separation of tryptic digest products. The resulting data are then converted into a 2-D topographic map where each spot represents a tryptic digest peptide. The 


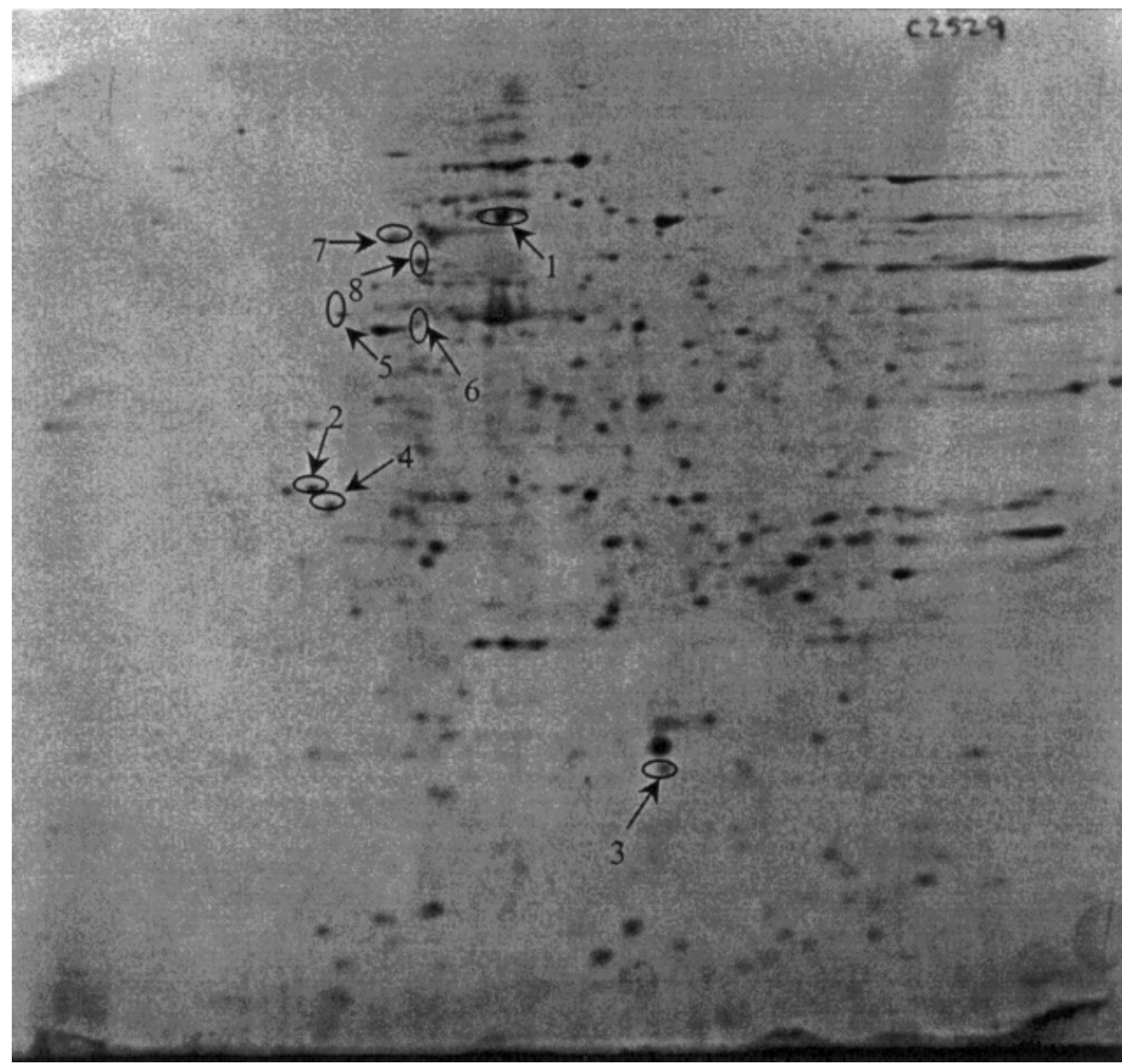

Figure 1. Coomassie Brilliant Blue stained image of 2-D gel electrophoresis of human erythroleukemia (HEL) cell extracts.

actual 2-D plot is color-coded for the identity of each spot, but only the grey scale version is presented in the manuscript. A detailed description of the 2-D topographic mapping technique has been discussed in previous work 31,32

Figure 2 shows the 2-D topographic map of the tryptic products from digestion of a $61 \mathrm{kDa}$ protein, HSP60. The TIC chromatogram displayed on the y-axis of Fig. 2 from cHPLC separation of the digest products shows a separation with limited resolution, mainly due to overloading of protein digest material on the column. In a random spot, the precise amount of material that can be injected before

\begin{tabular}{|c|c|c|c|}
\hline Spot No. & Protein Name & MW (Da) & $\mathrm{pI}$ \\
\hline 1 & Hucha(hsp-60) & 61055.0 & 5.70 \\
\hline 2 & Tropomyosin alpha chain & 32818.9 & 4.68 \\
\hline 3 & Stathmin (op18) & 17302.6 & 5.76 \\
\hline 4 & Tropomyosin (tm30-nm) & 29032.8 & 4.75 \\
\hline 5 & Vimentin & 41561.7 & 4.84 \\
\hline 6 & Troponin $\mathrm{T}$ & 34590.4 & 5.13 \\
\hline 7 & Matrin 3 & 47035.8 & 5.27 \\
\hline 8 & $\begin{array}{l}\text { Microfibrillar-associated } \\
\text { Protein } 1\end{array}$ & 51855.5 & 4.89 \\
\hline
\end{tabular}

saturation of the spectrum is generally not known. It is estimated that the average spot obtained by Coomassie Brilliant Blue staining contains $\sim 200 \mathrm{ng}$ of protein and that between 3-5 pieces were used in each analysis so that typically $0.6-1 \mu \mathrm{g}$ of protein was injected into the cHPLC for separation. Nevertheless, by using the 2-D plot, where the mass analysis serves as the second dimension, the tryptic products are clearly separated. In addition, there is a large amount of empty space in the plot so that even considerably more complicated digests could be analyzed. The tryptic peptides obtained in this plot are tabulated in Table 2, where 37 peptides have been observed which amounts to $\sim 54 \%$ coverage of the protein. The actual masses are tabulated using a cursor as shown in the plot, where the cursor on the 2-D map marks the spot to be analyzed. The mass spectrum corresponding to that marked by the cursor is shown on the $\mathrm{x}$-axis. The peak can then be expanded on the $\mathrm{x}$-axis and the mass of the peak determined by a second cursor. Each massto-charge ratio is then automatically placed in a list and the list transferred into the database for analysis. The result from the search is entered into a computer program written to convert the result into a table as shown in Table 2. The tryptic peptide peaks that appear in both the cHPLC/ESIMS and MALDI-MS experiments are indicated by a * in Tables 2 and 3, respectively.

An important issue is that although the cHPLC separation is of limited quality here, using the 2-D map we can readily 

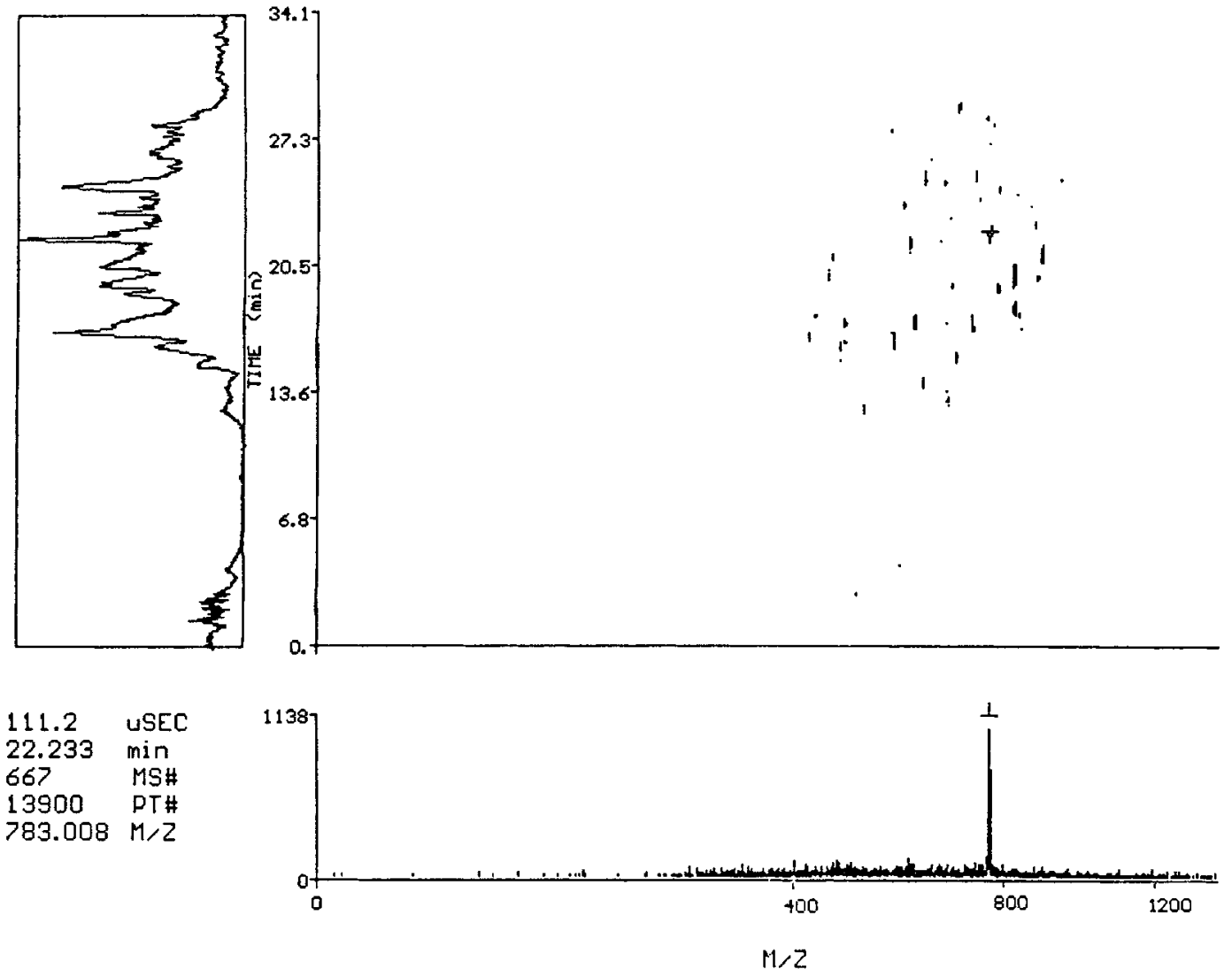

Figure 2. 2-D false-color image of the on-line cHPLC/ESI/IT-reTOF mass spectrometric analysis of the in-gel tryptic digest of protein spot No. 1 on the 2-D gels.
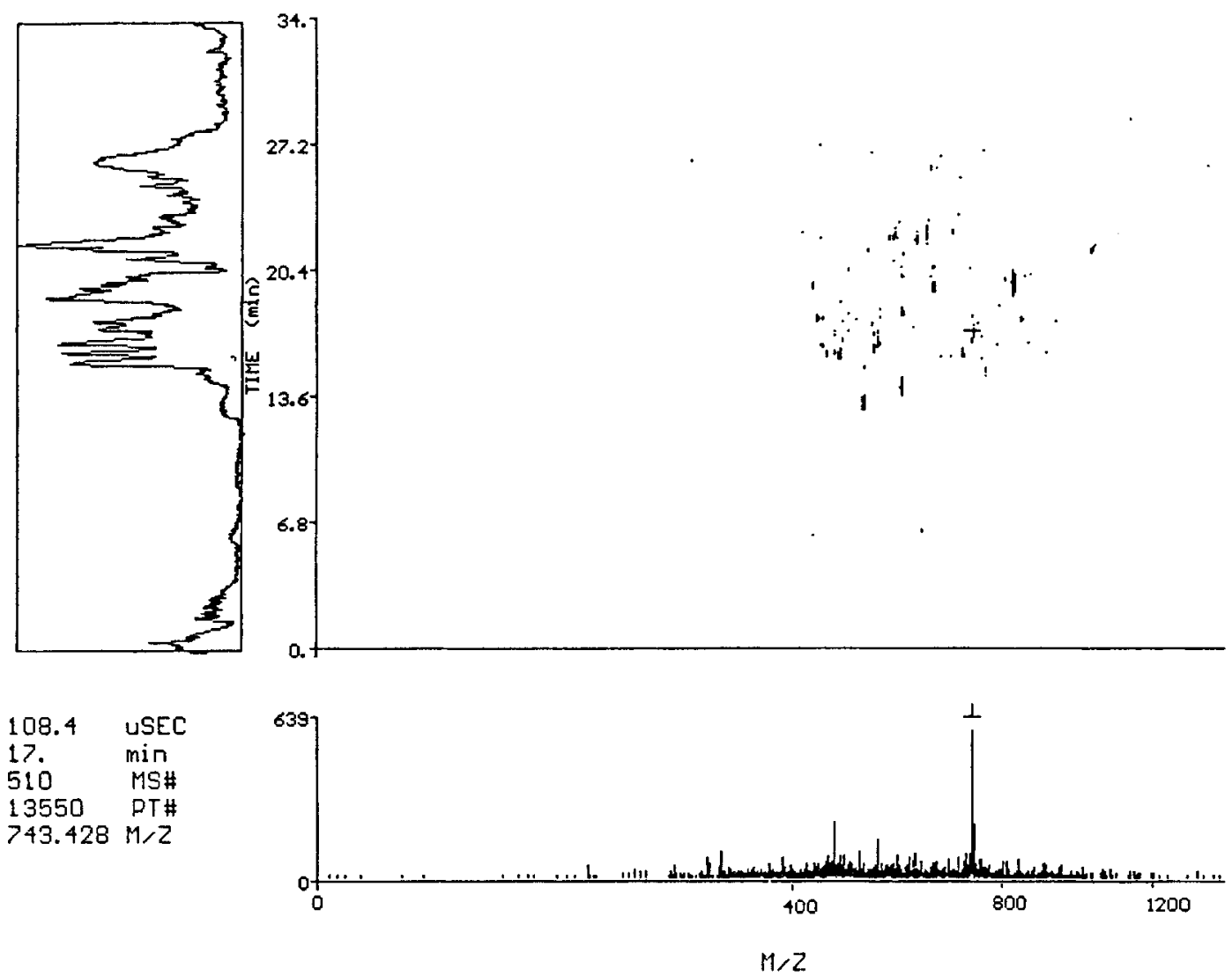

Figure 3. 2-D false-color image of the on-line cHPLC/ESI/IT-reTOF mass spectrometric analysis of the in-gel tryptic digest of protein spot No. 2 on the 2-D gels. 

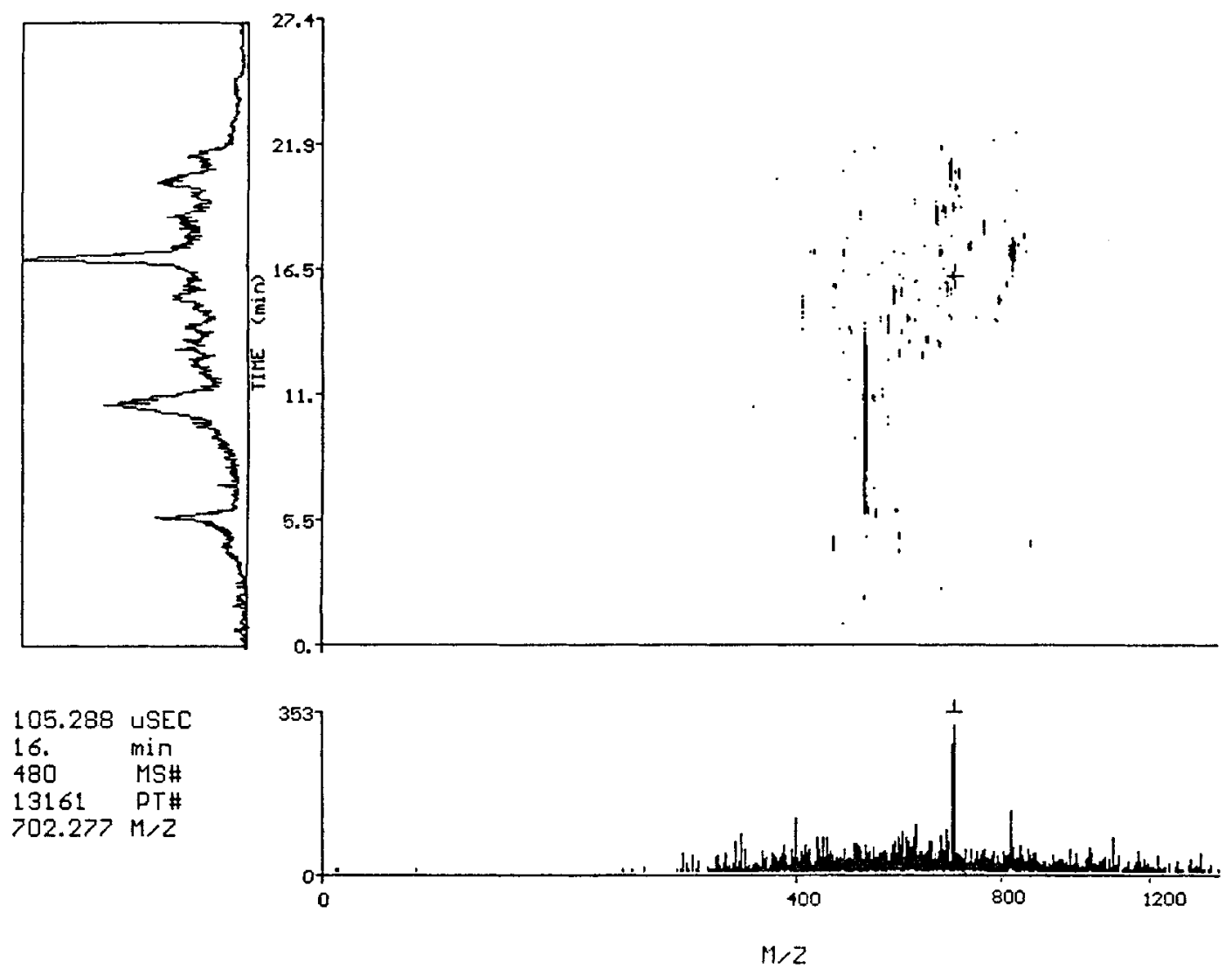

Figure 4. 2-D false-color image of the on-line cHPLC/ESI/IT-reTOF mass spectrometric analysis of the in-gel tryptic digest of protein spot No. 3 on the 2-D gels.
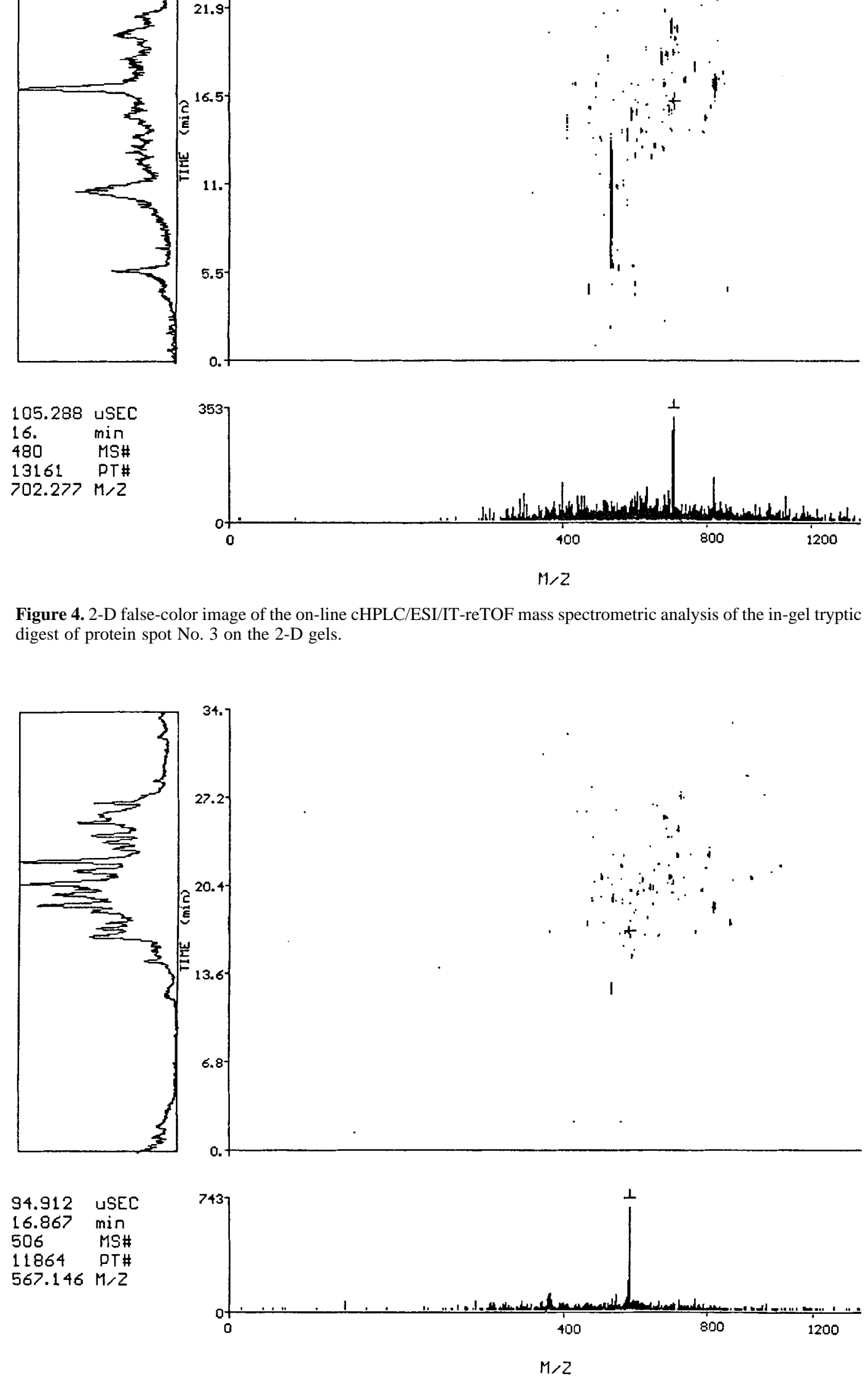

Figure 5. 2-D false-color image of the on-line cHPLC/ESI/IT-reTOF mass spectrometric analysis of the in-gel tryptic digest of protein spot No. 8 on the 2-D gels. 
Table 2. Database search result for the tryptic digest of protein spot No. 1 from HEL cell 2-D gels analyzed by capillary HPLC/ESI-ion trapreflectron TOFMS, which is shown in Fig. 2

$\begin{array}{rrrc}\mathrm{M}_{\text {meas }}(\mathrm{u}) & \mathrm{M}_{\text {calc }}(\mathrm{u}) & \Delta \mathrm{M}(\mathrm{u}) & \text { Residue } \\ 587.8 & 587.7 & 0.1 & 192-196 \\ * 635.6 & 636.7 & -1.1 & 32-37 \\ 688.9 & 689.8 & -0.9 & 76-82 \\ 785.8 & 786.0 & -0.2 & 463-469 \\ 805.6 & 806.0 & -0.4 & 353-359 \\ * 834.2 & 833.9 & 0.3 & 302-309 \\ 845.0 & 845.0 & 0.0 & 345-352 \\ 845.5 & 845.1 & 0.4 & 474-481 \\ * 855.9 & 856.0 & -0.1 & 134-141 \\ 873.7 & 874.1 & -0.4 & 10-16 \\ 902.1 & 902.1 & 0.0 & 397-405 \\ 913.0 & 913.2 & -0.2 & 293-301 \\ 943.1 & 942.2 & 0.9 & 463-470 \\ * 960.1 & 961.1 & -1.0 & 421-429 \\ 1148.7 & 1149.4 & -0.7 & 1-9 \\ 1190.5 & 1191.4 & -0.9 & 181-191 \\ 1215.5 & 1214.5 & 1.0 & 394-405 \\ 1216.7 & 1216.4 & 0.3 & 482-493 \\ 1230.8 & 1230.4 & 0.4 & 360-370 \\ 1345.4 & 1345.5 & -0.1 & 61-72 \\ 1390.8 & 1390.6 & 0.2 & 222-233 \\ 1428.6 & 1429.8 & -1.2 & 143-156 \\ 1444.6 & 1445.6 & -1.0 & 302-314 \\ 1488.1 & 1489.7 & -1.6 & 76-89 \\ 1506.5 & 1505.7 & 0.8 & 206-218 \\ 1522.2 & 1521.7 & 0.5 & 206-218 \\ 1558.6 & 1558.8 & -0.2 & 59-72 \\ 1573.5 & 1573.9 & -0.4 & 143-157 \\ 1586.2 & 1586.0 & 0.2 & 142-146 \\ 1713.2 & 1714.1 & -0.9 & 142-157 \\ 1723.7 & 1724.0 & -0.3 & 555-573 \\ 1773.8 & 1773.0 & 0.8 & 447-462 \\ * 1918.7 & 1920.2 & -1.5 & 251-268 \\ 1923.7 & 1924.2 & -0.5 & 206-221 \\ 2096.9 & 2048.4 & -0.5 & 250-268 \\ 2551.3 & 2097.5 & -0.8 & 291-310 \\ & 2551.1 & 0.2 & 134-157\end{array}$

$\quad$ Amino acid sequence and modifications
(K)KVGRK(G)
(K)FGADAR(A)
(K)DGVTVAK(S)
(K)IGIEIIK(R)
(K)DDAMLLK(G)
(K)APGFGDNR(K)
(K)VGEVIVTK(D)
(K)IPAMTIAK(N)
(K)GANPVEIR(R)
(R)QMRPVSR(V)
(K)LSDGVAVLK(V)
(K)VGLQVVAVK(A)
(K)IGIEIIKR(T)
(R)VTDALNATR(A)
(-)MLRLPTVFR(Q) 1Met-ox
(K)EIGNISDAMK(K)
(R)LAKLSDGVAVLK(V)
(K)NAGVEGSLIVEK(I)
(K)GKGDKAQIEKR(I)
(R)TVIIEQSWGSPK(V)
(R)GYISPYFINTSK(G)
(R)GVMLAVDAVIAELK(K)
(K)APGFGDNRKNQLK(D)
(K)DGVTVAKSIDLKDK(Y)
(K)TLNDELEIIEGMK(F)
(K)TLNDELEIIEGMK(F) 1Met-ox
(K)GRTVIIEQSWGSPK(V)
(R)GVMLAVDAVIAELKK(Q) 1Met-ox
(R)RGVMLAVDAVIAELK(K)
(R)RGVMLAVDAVIAELKK(Q)
(K)DPGMGAMGGMGGGMGGGMF(-) 1Met-ox
(R)CIPALDSLTPANEDQK(I)
(K)ISSIQSIVPALEIANAHR(K)
(K)TLNDELEIIEGMKFDR(G)
(K)KISSIQSIVPALEIANAHR(K)
(R)LKVGLQVVAVKAPGFGDNRK(N)
(K)GANPVEIRRGVMLAVDAVIAELKK(Q)

* Represents that the peak was also detected by MALDI-TOFMS.

separate out each peptide spot and achieve a substantial coverage of the protein for identification. The use of the cHPLC separation provides both separation and purification of the peptides. The result is elimination of many of the suppression effects observed in MALDI-MS. Table 3 displays the results of MALDI-MS of the tryptic digest of
HSP60 where only 12 major peaks are observed, providing a coverage of $30 \%$ of the protein. The quality of the MALDI mass spectra obtained depends very heavily on the matrix, sample preparation and the nature of the sample. ${ }^{33,34}$ In almost every case examined, HPLC-ESI-MS provided much improved protein coverage of the tryptic product identified.

Table 3. Database search result for the tryptic digests of protein spot No. 1 from HEL cell 2-D gels analyzed by MALDI-TOFMS

$\begin{array}{rrcc}\mathrm{M}_{\text {meas }}(\mathrm{u}) & \mathrm{M}_{\text {calc }}(\mathrm{u}) & \Delta \mathrm{M}(\mathrm{u}) & \text { Residue } \\ 504.7 & 504.6 & 0.1 & 360-364 \\ 532.2 & 531.6 & 0.6 & 390-393 \\ 554.7 & 553.6 & 1.1 & 88-91 \\ * 637.8 & 636.7 & 1.1 & 32-37 \\ * 835.6 & 833.9 & 1.7 & 302-309 \\ 846.2 & 845.1 & 1.1 & 474-481 \\ { }^{*} 857.8 & 857.0 & 0.8 & 10-16 \\ { }^{*} 961.4 & 961.1 & 0.3 & 421-429 \\ 1690.4 & 1692.0 & -1.6 & 555-573 \\ * 1920.3 & 1920.2 & 0.1 & 251-268 \\ * 2048.6 & 2048.4 & 0.2 & 250-268 \\ 2367.3 & 2366.8 & 0.5 & 269-290 \\ 2562.6 & 2561.7 & 0.9 & 97-121\end{array}$

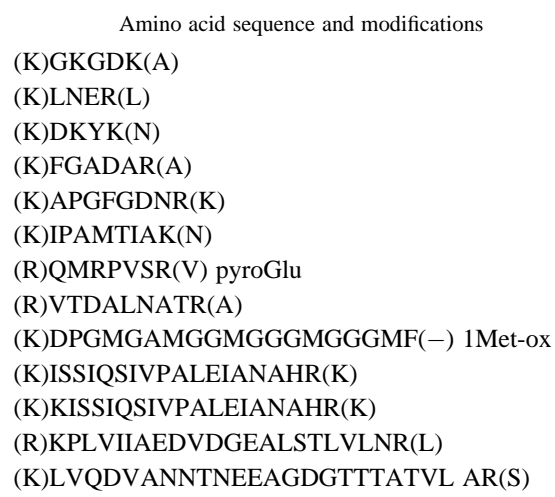

* Represents that the peak was also detected by capillary HPLC/ESI/IT/reTOFMS. 
Table 4. Database search result for the tryptic digests of protein spot No. 2 from HEL cell 2-D gels analyzed by capillary HPLC/ESI-ion trapreflectron TOFMS, which is shown in Fig. 3

\begin{tabular}{|c|c|c|c|c|}
\hline $\mathrm{M}_{\text {meas }}(\mathrm{u})$ & $\mathrm{M}_{\text {calc }}(\mathrm{u})$ & $\Delta \mathrm{M}(\mathrm{u})$ & Residue & Amino acid sequence and modifications \\
\hline 588.8 & 589.7 & -0.9 & $227-231$ & $(\mathrm{~K}) \operatorname{ILTDK}(\mathrm{L})$ \\
\hline 590.9 & 590.6 & 0.3 & $66-70$ & (K)DAQEK(L) \\
\hline 651.6 & 650.9 & 0.7 & $8-12$ & (K)MQMLK(L) \\
\hline 744.8 & 744.9 & -0.1 & $106-112$ & (R)LATALQK(L) \\
\hline 833.7 & 832.9 & 0.8 & $134-140$ & (R)ALKDEEK(M) \\
\hline 862.2 & 864.1 & -1.9 & $1-7$ & $(-)$ MEAIKKK $(\mathrm{M})$ \\
\hline 894.5 & 895.0 & -0.5 & $161-167$ & (R)KYEEVAR(K) \\
\hline 923.1 & 923.2 & -0.1 & $6-12$ & (K)KKMQMLK(L) \\
\hline 941.3 & 941.0 & 0.3 & $153-160$ & (K)HIAEEADR(K) \\
\hline 949.0 & 947.1 & 1.9 & $126-133$ & (R)GMKVIENR(A) \\
\hline 1068.7 & 1069.2 & -0.5 & $153-161$ & (K)HIAEEADRK(Y) \\
\hline 1131.5 & 1132.4 & -0.9 & $141-149$ & (K)MELQEIQLK(E) \\
\hline 1148.6 & 1148.3 & 0.3 & $50-59$ & (K)LKGTEDELDK(Y) \\
\hline 1156.8 & 1157.4 & -0.6 & $169-178$ & (K)LVIIEGDLER(T) \\
\hline 1183.0 & 1183.3 & -0.3 & $218-226$ & (K)EDKYEEEIK(I) \\
\hline 1243.3 & 1244.4 & -1.1 & $92-101$ & (R)IQLVEEELDR(A) \\
\hline 1258.2 & 1259.5 & -1.3 & $126-136$ & (R)GMKVIENRALK(D) \\
\hline 1284.9 & 1285.5 & -0.6 & $168-178$ & (R)KLVIIEGDLER(T) \\
\hline 1316.9 & 1317.4 & -0.5 & $78-90$ & (K)AADAEAEVASLNR(R) \\
\hline 1399.9 & 1400.6 & -0.7 & $91-101$ & (R)RIQLVEEELDR(A) \\
\hline 1442.9 & 1444.6 & -1.7 & $129-140$ & (K)VIENRALKDEEK(M) \\
\hline 1476.7 & 1476.7 & 0.0 & $141-152$ & (K)MELQEIQLKEAK(H) 1Met-ox \\
\hline 1548.8 & 1550.7 & -1.9 & $232-244$ & (K)LKEAETRAEFAER(S) \\
\hline 1644.8 & 1646.0 & -1.2 & $38-51$ & (K)QLEDELAAMQKKLK(G) \\
\hline 1722.8 & 1722.0 & 0.8 & $8-21$ & (K)MQMLKLDKENALDR(A) 1Met-ox \\
\hline 1755.1 & 1754.9 & 0.2 & $206-220$ & (K)SLEAQAEKYSQKEDK(Y) \\
\hline 2525.9 & 2526.9 & -1.0 & $141-161$ & (K)MELQEIQLEAKHIAEEA DRK(Y) 1Met-ox \\
\hline 2849.8 & 2851.2 & -1.4 & $7-30$ & (K)KMQMLKLDKENALDRA EQAEAEQK(Q) \\
\hline
\end{tabular}

It should be noted that for analysis of the tryptic digest products by MALDI-MS the masses can be directly input into the database search since the peptides are generally singly charged. However, the more limited coverage of the MALDI-MS data often provided for more than one possible match. In contrast, HPLC-ESI-MS applied to the protein spots in Table 1 generally resulted in a unique match.

Figures 3-5 show the 2-D topographic maps for a $32 \mathrm{kDa}$ protein, tropomyosin alpha chain, a $17 \mathrm{kDa}$ protein, OP18 or
Stathmin, and a $51 \mathrm{kDa}$ protein, microfibrillar-associated protein 1 , respectively. The peptides determined from the 2D map are tabulated in Tables 4-6. In the case of the $32 \mathrm{kDa}$ protein, 28 peptides were determined from the tryptic map, providing a coverage of $70 \%$, whereas 19 peptide peaks and a coverage of $54 \%$ were obtained by MALDI mass spectrometric analysis for this protein. For the $17 \mathrm{kDa}$ protein, 19 peptides were detected from the tryptic map, providing a coverage of $91 \%$, whereas 8 peptide peaks and a

Table 5. Database search result for the tryptic digest of protein spot No. 3 from HEL cell 2D gels analyzed by the capillary HPLC/ESI-ion trap-reflectron TOFMS, which is shown in Fig. 4

\begin{tabular}{crrrl}
$\mathrm{M}_{\text {meas }}(\mathrm{u})$ & $\mathrm{M}_{\text {calc }}(\mathrm{u})$ & $\Delta \mathrm{M}(\mathrm{u})$ & \multicolumn{1}{c}{ Residue } & \multicolumn{1}{c}{ Amino acid sequence and modifications } \\
587.5 & 588.7 & -1.2 & $71-75$ & $($ K)QLAEK(R) \\
674.9 & 674.8 & 0.1 & $10-14$ & (K)ELEKR(A) \\
891.2 & 890.0 & 1.2 & $1-9$ & $(-)$ ASSDIQVK(E) - Acet N \\
912.2 & 911.1 & 1.1 & $129-135$ & (K)HIEEVRK(N) \\
913.3 & 913.0 & 0.3 & $63-70$ & (K)SHEAEVLK(Q) \\
943.3 & 944.1 & -0.8 & $120-126$ & (K)LERLREK(D) \\
972.9 & 974.1 & -1.2 & $54-61$ & (K)LEAAEERR(K) \\
1075.1 & 1075.2 & -0.2 & $44-52$ & (K)DLSLEEIQK(K) \\
1153.6 & 1153.3 & 0.3 & $129-137$ & (K)HIEEVRKNK(E) \\
1165.5 & 1164.3 & 1.2 & $110-119$ & (K)ENREAQMAAK(L) \\
1166.3 & 1166.2 & 0.1 & $86-95$ & (K)AIEENNNFSK(M) \\
1201.9 & 1203.4 & -1.5 & $43-52$ & (K)KDLSLEEIQK(K) \\
1327.9 & 1327.5 & 0.4 & $30-41$ & (K)ESVPEFPLSPPK(K) \\
1389.6 & 1389.6 & 0.0 & $15-27$ & (R)ASGQAFELILSPR(S) \\
1412.3 & 1411.6 & 0.7 & $125-135$ & (R)EKDKHIEEVRK(N) \\
1477.3 & 1478.7 & -1.4 & $1-13$ & (-)MASSDIQVKELEK(R) \\
1544.0 & 1542.8 & 1.2 & $28-41$ & (R)SKESVPEFPLSPPK(K) \\
1676.1 & 1677.0 & -0.9 & $96-109$ & (K)MAEEKLTHKMEANK(E) 1Met-ox \\
1799.3 & 1799.1 & 0.2 & $28-43$ & (R)SKESVPEFPLSPPKKK(D)
\end{tabular}


Table 6. Database search result for the tryptic digest of protein spot No. 8 from HEL cell 2-D gels analyzed by capillary HPLC/ESI-ion trapreflectron TOFMS, which is shown in Fig. 5

\begin{tabular}{|c|c|c|c|c|}
\hline $\mathrm{M}_{\text {meas }}(\mathrm{u})$ & $\mathrm{M}_{\text {calc }}(\mathrm{u})$ & $\Delta \mathrm{M}(\mathrm{u})$ & Residue & Amino acid sequence and modifications \\
\hline 572.9 & 572.7 & 0.2 & $286-289$ & $(\mathrm{~K}) \mathrm{RIKR}(\mathrm{D})$ \\
\hline 574.8 & 574.7 & 0.1 & $325-329$ & $(\mathrm{~K}) \operatorname{VITNK}(\mathrm{A})$ \\
\hline 606.2 & 604.8 & 1.4 & $377-381$ & $(\mathrm{~K}) \mathrm{VMQVK}(\mathrm{N})$ \\
\hline 644.1 & 644.8 & -0.7 & $281-285$ & $(\mathrm{~K}) \operatorname{VRELK}(\mathrm{R})$ \\
\hline 729.8 & 729.9 & -0.1 & $419-425$ & (K)QKAAGVR(D) \\
\hline 780.0 & 780.9 & -0.9 & $101-106$ & (R)LARHRK(I) \\
\hline 802.0 & 801.0 & 1.0 & $281-286$ & (K)VRELKR(I) \\
\hline 826.8 & 827.0 & -0.2 & $335-340$ & (K)YKFLQK(Y) \\
\hline 843.2 & 844.0 & -0.8 & $286-291$ & (K)RIKRDR(E) \\
\hline 900.0 & 899.0 & 1.0 & $154-160$ & (R)QRAQERK(N) pyroGlu \\
\hline 963.0 & 964.2 & -1.2 & $1-9$ & $(-)$ MSVPSALMK(Q) \\
\hline 976.1 & 977.0 & -0.9 & $93-100$ & (R)ISEDVEER(L) \\
\hline 1038.8 & 1037.2 & 1.6 & $27-35$ & (K)GEISMEKVK(V) 1Met-ox \\
\hline 1040.9 & 1042.3 & -1.4 & $281-288$ & (K)VRELKRIK(R) \\
\hline 1088.3 & 1088.2 & 0.1 & $287-294$ & (R)IKRDREDR(E) \\
\hline 1160.8 & 1162.4 & -1.6 & $300-308$ & (K)EKAEIERMR(N) \\
\hline 1246.5 & 1247.3 & -0.8 & $292-301$ & (R)EDREALEKEK(A) \\
\hline 1261.7 & 1261.3 & 0.4 & $290-299$ & (R)DREDREALEK(E) \\
\hline 1279.3 & 1279.5 & -0.2 & $150-159$ & (R)GMMRQRAQER(K) 1Met-ox \\
\hline 1349.2 & 1349.7 & -0.5 & $325-336$ & (K)VITNKAVKGKYK(F) \\
\hline 1372.5 & 1373.6 & -1.1 & $210-221$ & (R)VTVQEREAEALK(Q) \\
\hline 1406.6 & 1407.7 & -1.1 & $150-160$ & (R)GMMRQRAQERK(N) 1Met-ox \\
\hline 1436.1 & 1435.7 & 0.4 & $149-159$ & (R)RGMMRQRAQER(K) 1Met-ox \\
\hline 1704.4 & 1704.0 & 0.4 & $148-160$ & (R)RRGMMRQRAQERK(N) \\
\hline 1820.0 & 1820.0 & 0.0 & $307-320$ & (R)MRNLTEEERRAELR(A) \\
\hline 1953.5 & 1955.3 & -1.8 & $27-43$ & (K)GEISMEKVKVKRYVS GK(R) 1Met-ox \\
\hline 2160.2 & 2161.6 & -1.5 & $372-390$ & (K)TILPKVMQVKNFGRS GRTK(Y) \\
\hline 2187.2 & 2185.5 & 1.7 & $283-299$ & (R)ELKRIKRDREDREAL EK(E) \\
\hline
\end{tabular}

coverage of $54 \%$ were obtained by MALDI mass spectrometric analysis for this protein. For the $51 \mathrm{kDa}$ protein, 28 peptides were detected from the LC/MS tryptic map, providing a coverage of $38 \%$, whereas 15 peaks and a coverage of $35 \%$ were obtained by MALDI-MS for this protein. In each case, a unique match was obtained from the database, providing identification of the protein. This was possible due to the clear separation of the peptides by the 2D maps, despite the limited separation provided by the cHPLC in this work. In addition, LC-ESI-MS and MALDIMS can be used to complement the information provided by each other so that the maximum coverage of the protein is obtained. The more complete the coverage of the protein, the higher the confidence one would expect in identification of the protein. In addition, the coverage of the tryptic map and the mass accuracy available in these experiments provides tentative identification of the presence of various modifications as shown in Tables 2-6. MS/MS in the ion trap could be used if necessary to confirm these modifications.

\section{CONCLUSIONS}

In conclusion, capillary HPLC separation of the tryptic digests of protein gel spots obtained from 2-D gel electrophoresis of HEL cells has been analyzed on-line using ESI/IT-reTOFMS. It has been demonstrated by using this method that fairly extensive coverage of the protein sequence can be determined for database searching and that a unique match can generally be identified. MALDI-MS provides less complete coverage than cHPLC/ESI-MS, although complementary information may often be obtained. Using a 2-D topographic mapping technique, the tryptic peptides can be identified and accurately mapped, despite the often incomplete resolution of peaks by the cHPLC separation. The method has been applied to several proteins over a mass range from 17 to $61 \mathrm{kDa}$ from a 2-D gel separation of a HEL cell line where over $90 \%$ coverage of the protein sequence is detected by the peptide map of a 17 $\mathrm{kDa}$ protein and greater than $50 \%$ coverage is obtained for a $61 \mathrm{kDa}$ protein. If the cell species, the approximate MW and pI range as determined by the 2-D gel method are entered into the database in addition to the tryptic map, then a unique match is identified in each case. This method may prove to be a complementary method to MALDI-MS for identification for proteins from 2-D gels, especially in cases where identification is uncertain and several possibilities may exist.

\section{Acknowledgements}

The authors gratefully acknowledge support of this work by the National Institutes of Health under grant No. 2-R01 GM49500-5 and the National Science Foundation under grant No. BIR-9513878.

\section{REFERENCES}

1. Eng JK, McCormack AL, Yates JR, J. Am. Soc. Mass Spectrom. 1994; 5: 976.

2. McCormack AL, Schieltz DM, Goode B, Yang S, Barnes G, Drubin D, Yates JR, Anal. Chem. 1997; 69: 767.

3. Ducret A, vanOostveen I, Eng JK, Yates JR, Aebersold R, Protein Science 1998; 7: 706.

4. vanOostveen I, Ducret A, Aebersold R, Anal. Biochem. 1997; 247: 310 .

5. Courchesne PL, Jones MD, Robinson JH, Spahr CS, McCracken S, Bentley DL, Luethy R, Patterson SD, Electrophoresis 1998; 19: 956. 
6. Wilm M, Shevchenko A, Houthaeve T, Breit S, Schweigerer L, Fotsis T, Mann M, Nature 1996; 379: 466

7. Neubauer G, Mann M, Anal. Chem. 1999; 71: 235.

8. Zugaro LM, Reid GE, Ji H, Eddes JS, Murphy AC, Burgess AW, Simpson RJ, Electrophoresis 1998; 19: 867.

9. Immler D, Gremm D, Kirsch D, Spengler B, Presek P, Meyer HE, Electrophoresis 1998; 19: 1015.

10. Reid GE, Rasmussen RK, Dorow DS, Simpson RJ, Electrophoresis 1998; 19: 946

11. Henzel JW, Billeci TM, Stults JT, Wong SC, Grimely C, Watanabe C, Proc. Nat. Acad. Sci. USA 1993; 90: 5011.

12. O'Connell KL, Stults JT, Electrophoresis 1997; 18: 349.

13. Schumacher M, Glocker MO, Wunderlin M, Przybylski M, Electrophoresis. 1996; 17: 848.

14. Williams K, LoPresti M, Stone K. Internal Protein Sequencing of SDS-PAGE Separated Proteins: Optimization of In-Gel Digest Protocol in Techniques in Protein Chemistry VIII, Marshak D. (ed). Academic Press, 1997.

15. Eckerskorn C, Grimm R, Electrophoresis 1996; 17: 899.

16. Cottrell JS, Peptide Res. 1994; 7: 115.

17. Zhang X, Herring CJ, Romano PR, Szczeparowska J, Brzeska H, Hinnebusch AG, Qin J, Anal. Chem. 1998; 70: 2050.

18. Nakayama H, Uchida K, Shinkai F, Shinoda T, Okuyama T, Seta K, Isobe T, J. Chromatogr. A 1996; 703: 279.

19. Rosenfeld J, Capdevielle J, Guillemot JC, Ferrara P, Anal. Biochem. 1992; 203: 173 .
20. Matsui NM, Smith DM, Clauser KR, Fichmann J, Andrews LE, Sullivan CM, Burlingame AL, Epstein LB, Electrophoresis 1997; 18: 409 .

21. Li G, Waltham M, Anderson NL, Unsworth E, Treston A Weinstein JN, Electrophoresis 1997; 18: 391.

22. Jensen ON, Larsen MR, Roepstorff P, Proteins: Structure, Function and Genetics Suppl. 1998; 2: 74.

23. Patterson SD, Aebersold R, Electrophoresis, 1995; 16: 1791.

24. Jungblutt P, Thiede B, Zimny-Arndt U, Muller E, Scheler C, Wittmann-Liebold B, Otto A, Electrophoresis 1996; 17: 839.

25. Strahler JR, Kuick R, Hanash SM. Protein Structure: A Practical Approach. Creighton T. (ed). IRL Press Ltd.: Oxford, 65-92.

26. Michael SM, Chien BM, Lubman DM, Anal. Chem. 1993; 65: 2614

27. Qian MG, Lubman DM, Anal. Chem. 1995; 67: 234A

28. Whittal R, L. Li, Anal. Chem. 1995; 67: 1950.

29. Zhu Y, He L, Srinavasan JR, Lubman DM, Rapid Commun. Mass Spectrom. 1997; 11: 987.

30. March RE, Hughes RJ. Quadrupole Storage Mass Spectrometry, John Wiley \& Sons: New York, 1989.

31. Hau J, Linscheid M, Spectrochim Acta B 1993; 48: E1047.

32. Li MX, Wu JT, Parus S, Lubman DM, J. Am. Soc. Mass Spectrom. 1998; 9: 701

33. Cohen SL, Chait BT, Anal. Chem. 1996; 68: 31.

34. Kratzer R, Eckerskorn C, Karas M, Lottspeich F, Electrophoresis 1998; 19: 1910. 